\title{
Area-based assessment of forest standing volume by field measurements and airborne laser scanner data
}

\author{
A. BARBATI $\dagger$, G. CHIRICI $\dagger$, P. CORONA $\uparrow$, A. MONTAGHI§ \\ and D. TRAVAGLINI*§ \\ $\dagger$ Dipartimento di Scienze dell'Ambiente Forestale e delle sue Risorse, University of \\ Tuscia, Viterbo, Italy \\ $\$$ EcoGeoFor, Laboratorio di Ecologia e Geomatica Forestale, Dipartimento di Scienze e \\ Tecnologie per l'Ambiente e il Territorio, University of Molise, Pesche (Isernia), Italy \\ §geoLAB, Laboratorio di Geomatica, Dipartimento di Scienze e Tecnologie Ambientali \\ Forestali, University of Florence, Firenze, Italy
}

\begin{abstract}
Airborne laser scanning (ALS) is increasingly applied as a tool for extracting forest inventory data. In recent years most applications for the assessment of forest standing volume rely on a single tree recognition approach, which generally gives satisfactory results in coniferous forests. The aim of this paper is to apply a rasterbased approach for the assessment of forest standing volume based on field measurements and a Digital Canopy Model (DCM) derived from ALS data. In addition, we explore the potential of hot spot analysis of DCM data for automatic forest gap detection, as a means to improve the accuracy of the estimation of forest standing volume by traditional estimation methods.
\end{abstract}

\section{Introduction}

During recent decades Airborne Laser Scanner (ALS) technologies have been established as the standard methods for high precision topographic data acquisition over large areas (Krabill et al. 1984, Bufton et al. 1991, Ritchie 1995, Glenn et al. 2006). ALS is an active remote sensing technique operating in the visible wavelength or near infrared wavelength. The sensor emits laser pulses and measures the time lag between the emission of the laser beam and the return of the reflected laser pulse. As a result, ALS systems provide elevation measurements of the sensed objects with high vertical precision.

ALS sensors are characterized by two main features: (1) the width of the laser beam diameter - larger than $1 \mathrm{~m}$ in large footprint instruments and smaller than $1 \mathrm{~m}$ in small footprint instruments; (2) recording of the round-trip time of the laser pulse - large and small footprint sensors may record the round-trip time of the first pulse or of the first and last pulses, whereas novel sensors can provide the power for the entire signal at the wavelength of the transmitted laser pulse (Bortolot and Wynne 2005, Hollaus et al. 2006, Wagner et al. 2006).

Laser pulses interact with tree canopies, bushes and the ground (Raber et al. 2002, Brandtberg 2007) and filtering techniques are used to separate the ground and canopy returns of the ALS backscattered signals. When the sensor records first pulses only, the height of the tree canopy can be calculated as the distance between the top of the forest canopy and the backscattered signals from the forest floor, recorded through

*Corresponding author. Email: davide.travaglini@unifi.it 